KREATIF

Jurnal IImiah
@Prodi Manajemen Fakultas Ekonomi Universitas Pamulang ISSN : $2339-0689$, E-ISSN : 2406-8616

J. KREATIF, Vol. 9 No. 1, Juni 2021 (Halaman 27-36)

Tersedia Online di :http://openjournal.unpam.ac.id/index.php/kreatif

\title{
PENGARUH KOMUNIKASI DAN GAYA KEPEMIMPINAN TERHADAP KINERJA PADA KARYAWAN YAYASAN AKY CIREUNDEU
}

\author{
Lia Asmalah ${ }^{1}$, Nurmin Arianto ${ }^{2}$, Heriyanto ${ }^{3}$ \\ ${ }^{1-2}$ Dosen dan ${ }^{3}$ Alumni Program Studi Manajemen Fakultas Ekonomi Universitas Pamulang \\ e-mail: dosen01118@unpam.ac.id
}

\begin{abstract}
ABSTRAK
Tujuan dari penelitian ini adalah untuk mengetahui bagaimana komunikasi dan gaya kepemimpinan secara parsial atau simultan mempengaruhi kinerja karyawan. Jenis penelitian ini adalah penelitian kuantitatif yang menggunakan metode deskriptif berdasarkan teknik pengumpulan data berdasarkan kuesioner.

Analisis data menggunakan uji validitas, uji reliabilitas, uji penerimaan klasik, analisis regresi, analisis koefisien korelasi, analisis koefisien determinasi dan uji hipotesis.

Berdasarkan hasil penelitian persamaan regresi $\mathrm{Y}=7.834+0.107 \mathrm{X} 1+0.679 \mathrm{X} 2$ menunjukkan bahwa komunikasi $\left(\mathrm{X}_{1}\right)$ dan gaya kepemimpinan $\left(\mathrm{X}_{2}\right)$ berpengaruh positif terhadap kinerja karyawan. Nilai koefisien determinasi atau faktor yang mempengaruhi juga sebesar 0,647 atau 64,7\%, dan sisanya 35,3\% dipengaruhi oleh faktor lain. Misalkan nilai yang diterima dari uji $\mathrm{F}>$ Tabel $\mathrm{F}$ atau (99.270> 2690) juga didukung oleh $\rho<$ Sig. 0,05 atau $(0,000<0,05)$. Oleh karena itu, H0 tolak, dan H3 diterima. Artinya, antara komunikasi dan gaya kepemimpinan memiliki pengaruh yang cukup besar terhadap kinerja karyawan Yayasan AKY Cireundeu.
\end{abstract}

Keywords : Komunikasi, Gaya Kepemimpinan, dan Kinerja Karyawan.

\section{ABSTRACT}

The purpose of this study was to determine how communication and leadership style partially or simultaneously affect employee performance. This type of research is a quantitative research using descriptive methods based on data collection techniques based on questionnaires.

Data analysis used validity test, reliability test, classical acceptance test, regression analysis, correlation coefficient analysis, determination coefficient analysis, and hypothesis testing.

Based on the results of the regression equation research $Y=7.834+0.107 X 1+$ $0.679 X 2$, it shows that communication $\left(X_{1}\right)$ and leadership style $\left(X_{2}\right)$ have a positive effect on employee performance. The coefficient of determination or the influencing factors is also 0.647 or $64.7 \%$, and the remaining $35.3 \%$ is influenced by other factors. Suppose the value received from the $F$ test $>$ Table $F$ or $(99,270>2690)$ is also supported by $\rho<$ Sig. 0.05 or (0.000 < 0.05). Therefore, HO is rejected, and H3 is accepted. This means that communication and leadership style has a considerable influence on the performance of the employees of the Khair Yasmin Cireundeu Charity Foundation.

Keywords : Communication And Leadership Style, Employee Performance

\section{PENDAHULUAN}

\section{Latar Belakang Masalah}

Sumber daya manusia adalah faktor yg sangat krusial lantaran keberhasilan suatu organisasi pada mencapai tujuannya sangat ditentukan oleh kinerja asal daya manusia yg 
optimal. Untuk menerima hasil kinerja yg baik bagi organisasi tentunya wajib didukung \& ditentukan oleh tindakan berdasarkan peran Manajemen Sumber Daya Manusia yg dimiliki perusahaan atau organisasi tersebut. Sumber daya manusia adalah salah satu faktor internal yg berperan krusial pada sukses tidaknya suatu organisasi pada mencapai tujuannya. Hasil observasi yg penulis lakukan pada Yayasan AKY Cireundeu tak jarang terjadi kesalahpahaman informasi antara pimpinan \& karyawan. Pasalnya, berita yg disampaikan pimpinan belum sepenuhnya hingga ke jajaran bawahan. apabila dipandang berdasarkan kurangnya komunikasi yg baik antara pimpinan \& bawahan yg mengakibatkan pimpinan mengalami kesulitan pada memahami impian \& kebutuhan karyawan begitu jua sebaliknya. Empat saluran komunikasi yg sudah diterapkan pada Yayasan AKY Cireundeu tercantum pada bawah ini.

Jenis Komunikasi di Yayasan Amal Khair Yasmin Cireundeu

\begin{tabular}{|c|c|c|c|}
\hline No & Jenis Komunikasi & $\begin{array}{l}\text { Frekuensi } \\
\text { Pertemuan }\end{array}$ & Keterangan \\
\hline 1 & $\begin{array}{lr}\text { Antara General } \\
\text { Manager dengan } \\
\text { seluruh Kepala } \\
\text { Unit }\end{array}$ & $\begin{array}{l}1 \text { bulan } \\
\text { sckali }\end{array}$ & $\begin{array}{l}\text { a. Evaluasi kinerja } \\
\text { perusahaan dalam satu } \\
\text { bulan. } \\
\text { b. Merencanakan program } \\
\text { kerja satu bulan berikutnya. }\end{array}$ \\
\hline 2 & $\begin{array}{lr}\text { Daily } & \text { Breafing } \\
\text { antara } & \text { Kepala } \\
\text { Unit } & \text { dengan } \\
\text { karyawan } & \end{array}$ & Setiap hari & $\begin{array}{l}\text { a. Membahas pekerjaan } \\
\text { harian. } \\
\text { b. Memberikan petunjuk } \\
\text { dalam melaksanakan tugas } \\
\text { dan tanggung jawab } \\
\text { maupun permasalahan yang } \\
\text { dihadapi. }\end{array}$ \\
\hline
\end{tabular}

Sumber: HRD Yayasan Amal Khair Yasmin Cireundeu, 2019

Berdasarkan pengetahuan tersebut, manajemen senior tidak pernah bertemu dengan ketua Yayasan AKY. Misalnya, belum pernah ada rapat pemegang saham untuk mengklarifikasi keluhan, kebutuhan pribadi karyawan, kritik atau saran dari karyawan. Pengaruh metode komunikasi dan keterampilan kepemimpinan pada staf Yayasan Yasmin Chirindeu harus dieksplorasi. Karena suasana komunikasi secara kolektif mencerminkan emosi karyawan, situasi ini pada akhirnya berdampak besar pada peningkatan vitalitas dan efisiensi setiap orang. Dalam suatu organisasi, komunikasi dapat diartikan sebagai proses menciptakan makna interaksi antar unit organisasi dalam organisasi untuk menciptakan, memelihara, dan mentransformasikan. Faktor komunikasi dan gaya kepemimpinan sangat penting untuk pondasi ini, karena semua elemen dasar tersebut saling berhubungan dan fleksibel. Selain itu, kita harus menghadapi Masyarakat Ekonomi ASEAN (MEA). Yayasan harus mampu meningkatkan kualitasnya dan bersaing dengan delapan organisasi lain yang berusaha. Selain itu, Yayasan AKY menuntut karyawannya untuk berprestasi dalam mencapai hasil yang berkualitas tinggi agar dapat bersaing dengan yayasan atau organisasi serupa.

Berangkat dari latar belakang masalah di atas maka penulis mengambil judul "Pengaruh Komunikasi dan Gaya Kepemimpinan Terhadap Kinerja Karyawan", pada Karyawan dari Semua Unit/Bagian ProgramYayasan AKY Cireundeu

\section{Rumusan dan Tujuan Penelitian:}

Tujuan penelitian berawal dari adanya rumusan masalah, maka dari itu yang menjadi rumusan masalah dalam penelitian ini adalah untuk mengetahui bagaimana komunikasi dan gaya kepemimpinan terhadap kinerja karyawan baik secara parsial ataupun simultan.

\section{TINJAUAN TEORI \\ Komunikasi}

Dalam bukunya Mulyana (2010) mengatakan bahwa dalam komunikasi antara dua orang, komunikasi terjadi ketika maknanya sama dan memahami penyebar (pembawa) 
penyebar (penerima pesan) pesan, orang yang berkomunikasi pada dasarnya harus memiliki arti yang sama, indikator yang digunakan untuk mengukur komunikasi oleh DeVito (2011), komunikasi menurun, komunikasi meningkat, dan komunikasi horizontal.

\section{Gaya Kepemimpinan}

Sesuai dengan apa yang dikatakan oleh Edison (2016) dimana gaya kepemimpinan adalah cara pemimpin bertindak dan atau bagaimana ia mempengaruhi anggotanya untuk mencapai tujuantujuan tertentu. Indikator dari gaya kempimpianan dalam penelitian ini menurut Edison (2016) yaitu: Memiliki strategi yang jelas dan dikomunikasi dengan baik, Memiliki strategi yang jelas dan dikomunikasi dengan baik, Merangsang anggota, Merangsang anggota, Menghargai perbedaan dan keyakinan.

\section{Kinerja}

Fahmi (2010), mengatakan bahwa kinerja adalah hasil yang diperoleh oleh suatu organisasi baik organisasi tersebut bersifat profit oriented dan non profit oriented yang dihasilkan selama satu periode. Adapun indikator yang digunakan dalam penelitiani ini menurut Mangkunegara (2011) menyebutkan indikator dari kinerja karyawan adalah sebagai berikut: Kualitas Kerja, Kuantitas Kerja, Pelaksanaan tugas, tanggun jawab.

\section{Kerangka Pemikiran}

Sikap yang baik dapat menjelaskan hubungan teoritis antar variabel yang diteliti. Variabel dalam penelitian ini ada dua yaitu Komunikas (X) sebagai variabel bebas dan Gaya Kepmimpinan (Y) sebagai variabel terikat. Hubungan kedua variabel ini merupakan hubungan (linier) dimana X mempengaruhi Y. Dengan kata lain dapat dikatakan bahwa Komunikasi dan gaya kepemimpinan akan mempengaruhi kinerja. Dan didukung oleh penelitian terdahulu yaitu oleh Zacharia (2020), Miftahul (2020), Lia Asmalah (2018), yang menyatakan bahwa Komunikasi dan gaya memiliki pengaruh terhadap kinerja.

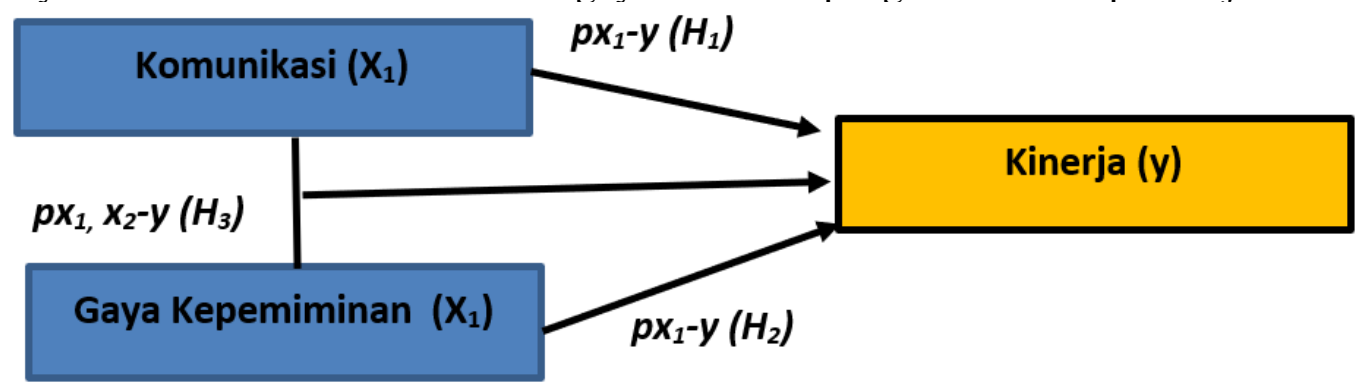

\section{METODE PENELITIAN}

\section{Jenis Penelitian}

Jenis penelitian ini adalah penelitian kuantitatif dengan pendekatan deskriptif. Dalam penelitian ini tidak ada perlakuan yang ditambahkan atau dikurangi dalam perolehan data di lapangan, penelitian ini menggambarkan suatu gejala, kondisi dan sifat situasi secara apa adanya tanpa adanya manipulasi pada waktu penyelidikan lapangan dilakukan.

\section{Tempat dan Waktu Penelitian}

Penelitian ini dilaksanakan di Yayasan yang berada di Ciputat, sedangkan waktu penelitian pada tahun 2020.

\section{Populasi dan Sampel}

Populasi dalam penelitian adalah karyawan Yayasan sebanyak 108 karyawan. Sample dalam penelitian ini adalah seluruh karyawan yang bekerja di Yayasan.

\section{Pengumpulan Data}

Didalam pengumpulan data kami menggunakan data primer yang terdiri dari Obervasi dan kuisioner serta wawancara kepada pimpinan perusahaan terkait dengan sejarah perusahaan, visi dan misi perusahaan, struktur organisasi, kebijakan dan tanggung jawab masing-masing bagian. 


\section{Teknik Analisis Data}

Didalam menganalisis data digunana analisi deskriptif dan analisis kuantitatif yang digunakan uji validitas dan uji reliablitas, uji asumsi klasik serta analisis regresi linier sederhana, uji korelasi, determinasi dan uji hipotesis (uji t).

\section{HASIL PENELITIAN}

\section{Hasil Penelitian Deskriptif Karekteristik Responden}

Dari hasil analisis deskriptif jenis kelamin dimana responden Laki-laki yang berjumlah 65 orang $(60,2 \%)$ dan responden Perempuan yang berjumlah 43 orang $(39,8 \%)$. Hal ini dapat digambarkan bahwa secara umum bahwa karyawan di dominasi oleh karyawan Laki-laki.

Dari analisis usia responden dimana usia antara 17-25 tahun sebanyak sebanyak 46 orang atau 42,6\%, yang berusia antara 26-35 tahun sebanyak 37 orang atau 34,3\%, yang berusia antara 36-45 tahun sebanyak 23 orang atau 21,3\% dan yang berusia $>45$ tahun sebanyak 2 orang atau $1,8 \%$.

Dan dari pendidikan dimana SMP Sederajat sebanyak 0 orang atau $0 \%$, berpendidikan SMA/SMK Sederajat 33 orang atau 30,6\%, berpendidikan Diploma sebanyak 8 orang atau $7,4 \%$, dan yang berpendidikan Sarjana (S1) sebanyak 67 orang atau 62\%. Hal ini menunjukan

bahwa persentase paling tinggi karyawan Yayasan AKY adalah yang berpendidikan sarjana dengan persentase $62 \%$ dan tidak terdapat lulusan dari SMP sederajat.

\section{Hasil Penelitian Deskriptif Variabel Penelitian Variabel Komunikasi}

Jawaban Responden Berdasar Pada Komunikasi (X1)

\begin{tabular}{|c|r|r|l|l|c|c|c|c|c|}
\hline \multirow{2}{*}{ No } & SS & S & KS & TS & STS & $\begin{array}{r}\text { Jml } \\
\text { bobot }\end{array}$ & Resp & Skor & Ket \\
\cline { 2 - 9 } & $\mathbf{5}$ & 4 & $\mathbf{3}$ & $\mathbf{2}$ & $\mathbf{l}$ & bob & & \\
\hline 1 & 33 & 39 & 23 & 7 & 6 & 410 & 108 & 3,8 & \\
\hline 2 & 28 & 41 & 6 & 8 & 5 & 403 & 108 & 3,7 & $\mathrm{~S}$ \\
\hline 3 & 19 & 39 & 32 & 12 & 6 & 377 & 108 & 3,5 & $\mathrm{~S}$ \\
\hline 4 & 22 & 46 & 20 & 17 & 3 & 391 & 108 & 3,6 & $\mathrm{~S}$ \\
\hline 5 & 20 & 38 & 31 & 14 & 5 & 378 & 108 & 3,5 & $\mathrm{~S}$ \\
\hline 6 & 26 & 45 & 23 & 7 & 7 & 400 & 108 & 3,7 & $\mathrm{~S}$ \\
\hline & 19 & 46 & 23 & 17 & 3 & 385 & 108 & 3,6 & $\mathrm{~S}$ \\
\hline 8 & 21 & 46 & 22 & 14 & 5 & 388 & 108 & 3,6 & $\mathrm{~S}$ \\
\hline 9 & 25 & 35 & 25 & 16 & 7 & 379 & 108 & 3,5 & $\mathrm{~S}$ \\
\hline 10 & 23 & 29 & 32 & 18 & 6 & 369 & 108 & 3,4 & $\mathrm{~S}$ \\
\hline Jumlah & 236 & 404 & 257 & 130 & 53 & 1080 & 3,59 \\
\hline
\end{tabular}

Jika dilihat dari tabel tersebut maka Skor rata yang diperoleh yaiu 3,59 hal ini termasuk pada rentang 3,40-4,19 dimana komunikasi yang di jalankan sudah baik, hal ini di buktikan dari skor tertinggi pada pernytaan 1 yaitu 3,8 dimana pemimppin selalu menampung aspirasi dan kritik serta saran dari karyawannya hal ini menandakan bahwa komunikasi yang dilaksanakan sudah baik. Disisi lain masih terdapat skor rendah yaitu pada pernytaan no 10 yaitu 3,4 dimana karyawan yang berkomunikasi aktif baik secara langsung atau tidak langsun melalui WA Group, hal ini membuktikan masih terdapat karyawan yang kurang aktif dalam berkomunikasi terlebih jika ada informasi yang dishare di group komunikasi banyak karyawan yang tidak merespon atau membacanya hal ini menandakan kmunikasi yang 
kurang lancar, maka dari itu di butuhkan suatu strategi agar komunikasi dapat lebih berjalan dengan lanca

Jawaban Responden Berdasar Pada Gaya Kepemimpinan (X2)

\begin{tabular}{|c|r|r|l|l|l|r|r|r|l|}
\hline \multirow{2}{*}{ No } & SS & $\mathbf{S}$ & KS & TS & STS & $\begin{array}{r}\text { Jml } \\
\text { bobot }\end{array}$ & Resp & Skor & Ket \\
\cline { 2 - 10 } & $\mathbf{5}$ & $\mathbf{4}$ & $\mathbf{3}$ & $\mathbf{2}$ & $\mathbf{l}$ & & & \\
\hline 1 & 28 & 42 & 20 & 10 & 8 & 396 & 108 & 3,7 & $\mathrm{~S}$ \\
\hline 2 & 36 & 33 & 19 & 14 & 6 & 403 & 108 & 3,7 & $\mathrm{~S}$ \\
\hline 3 & 28 & 42 & 22 & 13 & 3 & 403 & 108 & 3,7 & $\mathrm{~S}$ \\
\hline 4 & 22 & 42 & 28 & 10 & 6 & 388 & 108 & 3,6 & $\mathrm{~S}$ \\
\hline 5 & 28 & 39 & 23 & 12 & 6 & 395 & 108 & 3,7 & $\mathrm{~S}$ \\
\hline 6 & 22 & 39 & 29 & 10 & 8 & 381 & 108 & 3,5 & $\mathrm{~S}$ \\
\hline 7 & 18 & 39 & 31 & 13 & 7 & 372 & 108 & 3,4 & $\mathrm{~S}$ \\
\hline 8 & 20 & 46 & 22 & 12 & 8 & 382 & 108 &, 5 & $\mathrm{~S}$ \\
\hline 9 & 20 & 39 & 23 & 18 & 8 & 369 & 108 & 3,4 & $\mathrm{~S}$ \\
\hline 10 & 29 & 44 & 20 & 9 & 6 & 405 & 108 & 3,8 & $\mathrm{~S}$ \\
\hline Jumlah & 251 & 405 & 237 & 121 & 66 & \multicolumn{7}{|c|}{1080} & 3,6 \\
\hline
\end{tabular}

Tanggapan responden pada variabel gaya kepemimpinan diperoleh rata- rata skor 3,60 termasuk pada rentang skala 3,40-4,19 dengan kriteria baik, hal ini dibuktikan dengan skor tertinggi yaitu pada pernyataan no 10 yaiu 3,9 dimana Pimpinan meperdulikan hasil/target yang telah di ciapai unit program sehingga pemimpin selalu memberikan reward jika karyawan yang bisa menyelesaikan perkerjaan dengan baik dan sesuai dengan target yang telah ditetapkan. Sayang nya di sisilain masih terdapat skor rendah yaitu 3,4 pada pernytaan no 7 dimana pemimpin menentukan jadwal terselsaikanya suatu pekerjaan hal ini yang terkadang membuat karyawan merasa bingung waktu yang ditetapkan tidak jarang sangat terbatas sehingga membuat karyawan merasa tergesa-gesa dalam menyelesaiakan pekerjaanya sebaiknya pemimmpian bisa lebih memberikan waktu yang longgar agar karyawan bisa lebih fokus menyelesaikan pekerjaanya dengan baik.

Jawaban Responden Berdasar pada Kinerja $(\mathrm{Y})$

\begin{tabular}{|c|c|c|c|c|c|c|c|c|c|}
\hline \multirow{2}{*}{$N_{0}$} & SS & S & KS & TS & STS & $\begin{array}{r}\text { Jml } \\
\text { bobot }\end{array}$ & Resp & Skor & Ket \\
\hline 1 & $\mathbf{5}$ & 4 & 3 & 2 & 1 & & & \\
\hline 2 & 26 & 51 & 19 & 6 & 6 & 409 & 108 & 3,8 & S \\
\hline 2 & 28 & 51 & 12 & 9 & & 406 & 108 & 3,8 & S \\
\hline 3 & 19 & 44 & 22 & 3 & 10 & 373 & 108 & 3,5 & S \\
\hline 4 & 19 & 51 & 19 & 11 & 8 & 386 & 108 & 3,6 & S \\
\hline 5 & 19 & 50 & 21 & 11 & & 387 & 108 & 3,6 & S \\
\hline 6 & 24 & 48 & 17 & 12 & 7 & 394 & 108 & 3,6 & S \\
\hline 7 & 22 & 43 & 24 & 12 & 7 & 385 & 108 & 3,6 & S \\
\hline 8 & 30 & 44 & 15 & 15 & 4 & 405 & 108 & 3,8 & S \\
\hline 9 & 25 & 37 & 26 & 13 & 7 & 384 & 108 & 3,6 & S \\
\hline 10 & 25 & 46 & 22 & & 8 & 397 & 108 & 3,7 & S \\
\hline Jumlah & 237 & 465 & 197 & 109 & 72 & 1080 & 3,61 \\
\hline
\end{tabular}


Tanggapan responden pada variabel gaya kepemimpinan diperoleh rata- rata skor 3,61 termasuk pada rentang skala 3,40-4,19 dengan kriteria baik, dibuktikan dnegan skor tertinggi pada ppernyataan no 1 yaitu 3,8 dimana karyawan dapat menyelesaiakan tugas seusai dengan target yang telah di tentukan hal ini membuktikan bahwa masih terdapat karyawan yang bisa menyelesaikan ekerjaan dengan baik dan sesuai target, namun masih terdapat skor rendah yaitu 3,6 pada pernyataan no 9 dimana karyawan selalu hadir tepat waktu hal ini membuktikan masih terdapat karyawan yang datang tidak tepat waktu sehingga hal ini mempengaruhi kinerja dimana pekerjaan yang dikerjaan tidak sesuai target nya.

\section{Uji Instrument Penelitian Uji Validitas dan Reliabilitas}

\section{Rangkuman Hasil Uji Validitas Variabel Penelitian}

\begin{tabular}{l|c|c|c}
\hline \multicolumn{5}{c}{ Komunikasi } \\
\hline \multicolumn{1}{c|}{ Kuisioner } & R Hitung & R Tabel & Ket \\
\hline Kuisioner X1.1 & 0.724 & 0.195 & Valid \\
\hline Kuisioner X1.2 & 0.749 & 0.195 & Valid \\
\hline Kuisioner X1.3 & 0.657 & 0.195 & Valid \\
\hline Kuisioner X1.4 & 0.736 & 0.195 & Valid \\
\hline Kuisioner X1.5 & 0.802 & 0.195 & Valid \\
\hline Kuisioner X1.6 & 0.707 & 0.195 & Valid \\
\hline Kuisioner X1.7 & 0.652 & 0.195 & Valid \\
\hline Kuisioner X1.8 & 0.759 & 0.195 & Valid \\
\hline Kuisioner X1.9 & 0.715 & 0.195 & Valid \\
\hline Kuisioner X1.10 & 0.733 & 0.195 & Valid \\
\hline \multicolumn{5}{|c|}{ Gaya Kepemimpinan } \\
\hline Kuisioner X2.1 & 0.668 & 0.195 & Valid \\
\hline Kuisioner X2.2 & 0.754 & 0.195 & Valid \\
\hline Kuisioner X2.3 & 0.730 & 0.195 & Valid \\
\hline Kuisioner X2.4 & 0.798 & 0.195 & Valid \\
\hline Kuisioner X2.5 & 0.776 & 0.195 & Valid \\
\hline Kuisioner X2.6 & 0.780 & 0.195 & Valid \\
\hline Kuisioner X2.7 & 0.767 & 0.195 & Valid \\
\hline Kuisioner X2.8 & 0.666 & 0.195 & Valid \\
\hline Kuisioner X2.9 & 0.760 & 0.195 & Valid \\
\hline Kuisioner X2.10 & 0.732 & 0.195 & Valid \\
\hline & \multicolumn{5}{|c|}{ Kinerja } & 0.195 & Valid \\
\hline Kuisioner X2.1 & 0,779 & 0.195 & Valid \\
\hline Kuisioner X2.2 & 0,731 & 0.195 & Valid \\
\hline Kuisioner X2.3 & 0,770 & 0.195 & Valid \\
\hline Kuisioner X2.4 & 0,802 & 0.195 & Valid \\
\hline Kuisioner X2.5 & 0,757 & Valid \\
\hline Kuisioner X2.6 & 0,736 & 0.195 & Valid \\
\hline Kuisioner X2.7 & 0,786 & Valid \\
\hline Kuisioner X2.8 & 0,844 & & Valid \\
\hline
\end{tabular}

Berdasarkan tabel tersebut maka semua item pertanyaan variabel kualitas pelayanan semuanya berada diatas angka 0,265 nilai atau ( $\left.r_{\text {hitung }}>r_{\text {tabel }}\right)$,

Uji Relibilitas

\begin{tabular}{|l|c|c|c|}
\hline \multicolumn{1}{|c|}{ Variabel } & $\begin{array}{c}\text { Cronbatc } \\
\text { hAlpha }\end{array}$ & $\begin{array}{c}\text { Standar } \\
\text { Cronbatch } \\
\text { Alpha }\end{array}$ & Keputusan \\
\hline Komunikasi (X1) & 0,899 & 0.600 & Reliabel \\
\hline Gaya Kepemimpinan (X2) & 0,909 & 0.600 & Reliabel \\
\hline Kinerja (Y) & 0,915 & 0.600 & Reliabel \\
\hline
\end{tabular}

Berdasarkan hasil pengujian pada tabel di atas, menunjukkan bahwa variabel komunikasi $\left(\mathrm{X}_{1}\right)$, gaya kepemimpinan $\left(\mathrm{X}_{2}\right)$ dan kinerja karyawan $(\mathrm{Y})$ dinyatakan reliabel, hal itu 
dibuktikan dengan masing-masing variabel memiliki nilai Chronbath Alpha lebih besar dari 0,600 .

\section{Uji Asumsi Klasik}

Uji Normalitas

Hasil Uji Normalitas

\begin{tabular}{|c|c|c|}
\hline \multicolumn{3}{|c|}{ One-Sample Kolmogorov Smirnov Test } \\
\hline & & $\begin{array}{l}\text { Unstandardiz } \\
\text { edResidual }\end{array}$ \\
\hline \multicolumn{2}{|l|}{$\mathrm{N}$} & 108 \\
\hline \multirow[t]{2}{*}{ Normal Parameters ${ }^{\mathrm{a}, \mathrm{b}}$} & Mean & .0000000 \\
\hline & Std. Deviation & 3.87656311 \\
\hline \multirow{3}{*}{$\begin{array}{l}\text { Most Extreme } \\
\text { Differences }\end{array}$} & Absolute & .074 \\
\hline & Positive & .074 \\
\hline & Negative & -.073 \\
\hline \multicolumn{2}{|l|}{ Test Statistic } & .074 \\
\hline \multicolumn{2}{|l|}{ Asymp. Sig. (2-tailed) } & $.184^{\circ}$ \\
\hline \multicolumn{3}{|c|}{ a. Test distribution is Normal. } \\
\hline \multicolumn{3}{|l|}{ b. Calculated from data. } \\
\hline \multicolumn{3}{|c|}{ c. Lilliefors Significance Correcti } \\
\hline
\end{tabular}

Pada tabel di atas, diperoleh nilai signifikansi $\alpha=0,184$ dimana nilai tersebut lebih besar dari nilai $\alpha=0,050$ atau $(0,184>0,050)$. Dengan demikian maka asumsi distribusi persamaan pada uji iniadalah normal.

Uji Multikolinieritas

\begin{tabular}{|c|c|c|c|c|c|c|c|}
\hline \multicolumn{8}{|c|}{ Uji Multikolinieritas } \\
\hline \multirow[b]{2}{*}{ Model } & \multicolumn{2}{|c|}{$\begin{array}{l}\text { Unstandardized } \\
\text { Coefficients }\end{array}$} & \multirow{2}{*}{$\begin{array}{c}\begin{array}{r}\text { Standardized } \\
\text { Coefficients }\end{array} \\
\text { Beta } \\
\end{array}$} & \multirow[b]{2}{*}{$\mathrm{T}$} & \multirow[b]{2}{*}{ Sig. } & \multicolumn{2}{|c|}{$\begin{array}{l}\text { Collinearity } \\
\text { Statistics }\end{array}$} \\
\hline & B & Std. Error & & & & Tolerance & VIF \\
\hline 1 (Constant) & 7.834 & 2.185 & & 3.585 & .001 & & \\
\hline Komunikasi & .107 & .093 & .106 & 1.151 & .252 & .386 & 2.592 \\
\hline Gaya Kepemimpinan & .679 & .087 & .723 & 7.820 & .000 & .386 & 2.592 \\
\hline
\end{tabular}

Hasil pengujian multikolinieritas pada tabel di atas diperoleh nilai tolerance masing-masing variabel bebas yaitu komunikasi sebesar 0,386 dan gaya kepemimpinan sebesar 0,386, dimana kedua nilai tersebut kurang dari 1, dan nilai Variance Inflation Factor (VIF) variable komunikasi sebesar 2,952 serta gaya kepemimpinan sebesar 2,952 dimana nilai tersebut kurang dari 10. Dengan demikian model regresi ini tidak ada multikoliniearitas.

\section{Uji Regresi Linier Berganda}

\begin{tabular}{|c|c|c|c|c|c|}
\hline \multicolumn{6}{|c|}{ Coefficients ${ }^{\mathrm{a}}$} \\
\hline \multirow[b]{2}{*}{ Model } & \multicolumn{2}{|c|}{$\begin{array}{l}\text { Unstandardized } \\
\text { Coefficients }\end{array}$} & \multirow{2}{*}{$\begin{array}{l}\text { Standardized } \\
\text { Coefficients }\end{array}$} & \multirow[b]{2}{*}{$\mathrm{t}$} & \multirow[b]{2}{*}{ Sig. } \\
\hline & $B$ & Std. Error & & & \\
\hline 1 (Constant) & 7.834 & 2.185 & & 3.585 & .001 \\
\hline Komunikasi & .107 & .093 & .106 & 1.151 & .252 \\
\hline $\begin{array}{l}\text { Gaya } \\
\text { Kepemimpinan }\end{array}$ & .679 & .087 & .723 & 7.820 & .000 \\
\hline \multicolumn{6}{|c|}{ a. Dependent Variable: Kinerja } \\
\hline
\end{tabular}


Berdasarkan hasil analisis perhitungan regresi pada tabel di atas, maka dapat diperoleh persamaan regresi $\mathrm{Y}=7,834+0,107 \mathrm{X}_{1}+0,679 \mathrm{X}_{2}$. Dari persamaan di atas maka dapat disimpulkan sebagai berikut:

a) Nilai konstanta sebesar 7,834 diartikan bahwa jika variabel komunikasi $\left(\mathrm{X}_{1}\right)$ dan gaya kepemimpinan $\left(\mathrm{X}_{2}\right)$ tidak ada maka telah terdapat nilai kinerja karyawan (Y) sebesar 7,834 point.

b) Nilai komunikasi (X1) 0,107 diartikan apabila konstanta tetap dan tidak ada perubahan pada variable gaya kepemimpinan $\left(\mathrm{X}_{2}\right)$, maka setiap perubahan 1 unit pada variabel komunikasi $\left(\mathrm{X}_{1}\right)$ akan mengakibatkan terjadinya perubahan pada kinerja karyawan $(\mathrm{Y})$ sebesar 0,107 point.

c) Nilai gaya kepemimpinan (X2) 0,679 diartikan apabila konstanta tetap dan tidak ada perubahan pada variabel komunikasi $\left(\mathrm{X}_{1}\right)$, maka setiap perubahan 1 unit pada variabel gaya kepemimpinan $\left(\mathrm{X}_{2}\right)$ akan mengakibatkan terjadinya perubahan pada kinerja karyawan (Y) sebesar 0,679 point.

\section{Uji Regresi Korelasi}

\begin{tabular}{|c|c|c|c|c|}
\hline \multicolumn{5}{|c|}{ Correlations } \\
\hline & & Komunikasi & Gaya Kepemimpinan & Kinerja \\
\hline \multirow[t]{3}{*}{ Komunikasi } & $\begin{array}{l}\text { Pearson } \\
\text { Correlation }\end{array}$ & 1 & $.784^{\circ *}$ & $.673^{64}$ \\
\hline & Sig. (2-tailed) & & .000 & .000 \\
\hline & $\mathrm{N}$ & 108 & 108 & 108 \\
\hline \multirow[t]{3}{*}{$\begin{array}{l}\text { Gaya } \\
\text { Kepemimpinan }\end{array}$} & \begin{tabular}{|l} 
Pearson \\
Correlation \\
\end{tabular} & $.784^{\circ 4}$ & 1 & $.806^{44}$ \\
\hline & Sig. (2-tailed) & .000 & & .000 \\
\hline & $\mathrm{N}$ & 108 & 108 & 108 \\
\hline \multirow[t]{3}{*}{ Kinerja } & $\begin{array}{l}\text { Pearson } \\
\text { Correlation }\end{array}$ & $.673^{\circ 4}$ & $.806^{\circ *}$ & 1 \\
\hline & Sig. (2-tailed) & .000 & .000 & \\
\hline & $\mathrm{N}$ & 108 & 108 & 108 \\
\hline
\end{tabular}

Dari tabel di atas dapat disimpulkan bahwa

a. Koefisien korelasi sebesar 0,673 ( $\mathrm{r}$ hitung) artinya $\mathrm{r}$ hitung lebih besar dari $\mathrm{r}$ tabel ( $\mathrm{r}$ hitung $>\mathrm{r}$ Tabel $=0,673>0,195)$ maka variabel komunikasi dan variabel kinerja memiliki tingkat hubungan yangkuat.

b. Berdasarkan pada hasil pengujian pada tabel di atas, diperoleh nilai Koefisien korelasi sebesar 0,806 ( $\mathrm{r}$ hitung) artinya $\mathrm{r}$ hitung lebih besar dari $\mathrm{r}$ tabel $(\mathrm{r}$ hitung $>\mathrm{r}$ tabel $=$ $0,806>0,95$ ) maka kedua variabel yaitu gaya kepemimpinan dengan kinerja mempunyai tingkat hubungan yang kuat.

c. Karena $r$ hitung atau pearson correlations dalam analisis ini bernilai positif maka artinya hubungan antar variabel bersifat positif atau dengan kata lain semakin baiknya komunikasi dan gaya kepemimpinan maka semakin baik pula kinerja dari karyawan.

\section{Uji Korelasi dan Determinasi}

\begin{tabular}{|c|c|c|c|c|c|c|c|c|c|}
\hline \multicolumn{10}{|c|}{ Model Summary } \\
\hline \multirow[b]{2}{*}{ Model } & \multirow[b]{2}{*}{$\mathrm{R}$} & \multirow[b]{2}{*}{$\begin{array}{c}R \\
\text { Square }\end{array}$} & \multirow{2}{*}{$\begin{array}{l}\text { Adjusted } \\
\text { RSquare }\end{array}$} & \multirow{2}{*}{$\begin{array}{c}\text { Std. Error of } \\
\text { the } \\
\text { Estimate }\end{array}$} & \multicolumn{5}{|c|}{ Change Statistics } \\
\hline & & & & & $\begin{array}{c}\text { R Square } \\
\text { Change }\end{array}$ & \begin{tabular}{c|}
$F$ \\
Change
\end{tabular} & df1 & df 2 & $\begin{array}{c}\text { Sig. F } \\
\text { Change }\end{array}$ \\
\hline 1 & $.809^{\mathrm{a}}$ & .654 & .647 & 3.913 & .654 & 99.270 & 2 & 105 & .000 \\
\hline \multicolumn{10}{|c|}{ a. Predictors: (Constant), Gaya kepemimpinan, Komunikasi } \\
\hline
\end{tabular}


Hasil pengujian pada tabel di atas, diperoleh nilai Koefisien determinasi sebesar 0,647 maka dapat disimpulkan bahwa variabel komunikasi dan gaya kepemimpinan berpengaruh terhadap variabel kinerja karyawan sebesar 64,7\% sedangkan sisanya sebesar 35,3\% dipengaruhi olehfaktor lain yang tidak dilakukan penelitian. Karena nilai $\mathrm{r}$ square positif maka dapat disimpulkan bahwa X1 dan X2 secara simultan memiliki pengaruh terhadap Y serta memiliki pengaruh yang kuat karena nilai $r$ square mendekati angka 1

\section{Uji Hipotesis Parsial}

\begin{tabular}{|c|c|c|c|c|c|}
\hline \multicolumn{6}{|c|}{ Coefficients $^{a}$} \\
\hline \multirow[b]{2}{*}{ Model } & \multicolumn{2}{|c|}{$\begin{array}{l}\text { Unstandardized } \\
\text { Coefficients }\end{array}$} & \multirow{2}{*}{$\begin{array}{c}\begin{array}{c}\text { Standardized } \\
\text { Coefficients }\end{array} \\
\text { Beta }\end{array}$} & \multirow[t]{2}{*}{$\mathrm{t}$} & \multirow[t]{2}{*}{ Sig. } \\
\hline & $\mathrm{B}$ & Std. Error & & & \\
\hline 1 1 $\begin{array}{c}\text { (Constan } \\
\mathrm{t})\end{array}$ & 11.966 & 2.655 & & 4.507 & .000 \\
\hline $\begin{array}{c}\text { Komunik } \\
\text { asi }\end{array}$ & .674 & .072 & .673 & 9.362 & .000 \\
\hline
\end{tabular}

Berdasarkan pada hasil pengujian pada tabel di atas diperoleh nilai $\mathrm{t}$ hitung $>\mathrm{t}$ tabel atau $(9,362>1,983)$. Hal tersebut juga diperkuat dengan nilai $\rho$ value $<$ Sig. Maka komunikasi memiliki pengaruh terhadap kinerja.

\begin{tabular}{|c|c|c|c|c|c|}
\hline \multicolumn{6}{|c|}{ Coefficients $\mathrm{s}^{\mathrm{a}}$} \\
\hline \multirow[b]{2}{*}{ Mode1 } & \multicolumn{2}{|c|}{$\begin{array}{l}\text { Unstandardized } \\
\text { Coefficients }\end{array}$} & $\begin{array}{l}\text { Standardized } \\
\text { Coefficients }\end{array}$ & \multirow[t]{2}{*}{$\mathrm{t}$} & \multirow[t]{2}{*}{ Sig } \\
\hline & B & Std. Error & $\begin{array}{c}\text { Bet } \\
\mathrm{a}\end{array}$ & & \\
\hline \begin{tabular}{l|l}
11 & (Constant) \\
\end{tabular} & 8.849 & 2.003 & & 4.419 & .000 \\
\hline $\begin{array}{l}\text { Gaya } \\
\text { kepemimpinan }\end{array}$ & .757 & .054 & .806 & 14.022 & .000 \\
\hline
\end{tabular}

Berdasarkan pada hasil pengujian pada tabel di atas diperoleh nilai $\mathrm{t}$ hitung $>\mathrm{t}$ tabel atau $(14,022>1,983)$. Hal tersebut juga diperkuat dengan nilai $\rho$ value $<$ Sig. Maka Gaya kepemimpinan memiliki pengaruh terhadap kinerja.

\section{Uji Hipotesis Simultan}

\begin{tabular}{|c|c|c|c|c|c|}
\hline \multicolumn{6}{|c|}{ ANOVA $^{a}$} \\
\hline Model & $\begin{array}{l}\text { Sum of } \\
\text { Squares }\end{array}$ & df & $\begin{array}{c}\text { Mean } \\
\text { Square }\end{array}$ & $\mathrm{F}$ & Sig. \\
\hline $\begin{array}{c}1 \\
\begin{array}{c}\text { Regressio } \\
\mathrm{n}\end{array} \\
\end{array}$ & 3040.439 & 2 & 1520.220 & 99.270 & \begin{tabular}{|c|}
.000 \\
$\mathrm{~b}$ \\
\end{tabular} \\
\hline Residual & 1607.968 & 105 & 15.314 & & \\
\hline Total & 4648.407 & 107 & & & \\
\hline \multicolumn{6}{|c|}{ a. Dependent Variable: Kinerja } \\
\hline \multicolumn{6}{|c|}{ b. Predictors: (Constant), Gaya kepemimpinan, Komunikasi } \\
\hline
\end{tabular}

Berdasarkan pada hasil pengujian pada tabel di atas diperoleh nilai $\mathrm{F}$ hitung $>\mathrm{F}$ tabel atau $(99,270>2,690)$, hal ini juga diperkuat dengan $\rho$ value $<$ Sig. Sehingga komunikasi dan gaya kepemimpinan memiliki pengaruuh terhadap kinerja.

\section{KESIMPULAN}

Berdasarkan hasil penelitian dan analisis data maka:

1. Komunikasi berpengaruh signifikan terhadap kinerja karyawan dengan persamaan uji hipotesis diperoleh nilai t hitung $>\mathrm{t}$ tabel atau $(9,362>1,983)$.

2. Gaya kepemimpinan berpengaruh signifikan terhadap kinerja karyawan dengan uji hipotesis diperoleh nilai $t$ hitung $>t$ tabel atau $(14,022>1,983)$.

3. Komunikasi dan Gaya Kepemimpinan dilihat dari Uji hipotesis diperoleh nilai $\mathrm{F}$ hitung $>$ Ftabel atau $(99,270>2,690)$, hal ini juga diperkuat dengan $\rho$ value $<$ Sig. 


\section{DAFTAR PUSTAKA}

Arianto, Nurmin, and Hadi Kurniawan. "Pengaruh Motivasi dan Lingkungan Kerja Terhadap Kinerja Karyawan." JENIUS (Jurnal Ilmiah Manajemen Sumber Daya Manusia) 3.3 (2020): 312-321.

Arianto, Nurmin, and Wita Pebriani. "Pengaruh Kepemimpinan Dan Motivasi Terhadap Kinerja Karyawan (Studi Pada Karyawan Direktorat Sumber Daya Di Sebuah Universitas Swasta Jakarta Barat)." Proceedings Universitas Pamulang 1.1 (2020).

Arianto, Nurmin. "Kepemimpinan dan Komunikasi Pengaruhnya Terhadap Kinerja dengan Kepuasan Kerja Sebagai Variabel Intervening." KREATIF: Jurnal Ilmiah Prodi Manajemen Universitas Pamulang 8.1 (2020): 124-137.

Arianto, Nurmin. "Pengaruh Kepemimpinan Terhadap Kinerja dan Kepuasan Kerja Karyawan Pada PT. Gada Rajawali Dunia." JENIUS (Jurnal Ilmiah Manajemen Sumber Daya Manusia) 1.3 (2018).

Devito, J. (2011). Komunikasi Antar Manusia. Pamulang-Tangerang Selatan: Karisma Publishing Group.

Edison. (2016). Manajemen Sumber Daya Manusia. Bandung: Alfabeta.

Fahmi, I. (2010). Manajemen Resiko. Bandung: Alfabeta.

Mangkunegara. (2011). Manajemen Sumber Daya Perusahaan. Bandung: PT . Remaja Rosda karya.

Mulyana, D. (2010). Imu Komunikasi : Suatu Pengantar. Bandung: RemajaRosdakarya.

Noviyanti, Iis, et al. "Marketing Intelligence Implementation for Supply Chain Mannagemnt of Mix Products That Affect the Purchasing Decision on Citra Karisma, Yogyakarta." Int. J Sup. Chain. Mgt Vol 9.3 (2020): 1235. 